\title{
Importance of Pore Structure and Surface Chemistry in Carbon Dioxide Adsorption on Electrospun Carbon Nanofibers
}

\author{
Yu-Chun Chiang, ${ }^{1,2^{*}}$ Shang-Tse Lee, ${ }^{1}$ Yan-Juin Leo, ${ }^{1}$ and Te-Lung Tseng ${ }^{1}$ \\ ${ }^{1}$ Department of Mechanical Engineering, Yuan Ze University, \\ 135 Yuan-Tung Rd., Chung-Li, Taoyuan 32003, Taiwan \\ ${ }^{2}$ Fuel Cell Center, Yuan Ze University, 135 Yuan-Tung Rd., Chung-Li, Taoyuan 32003, Taiwan
}

(Received April 16, 2019; accepted May 20, 2020)

Keywords: carbon nanofiber, adsorption, carbon dioxide, carbonization

The development of carbon dioxide $\left(\mathrm{CO}_{2}\right)$ capture technology is of great urgency for reducing the emission of $\mathrm{CO}_{2}$ to the atmosphere and mitigating global warming. Polyacrylonitrilebased electrospun carbon nanofibers were prepared in this study at different carbonization temperatures for $\mathrm{CO}_{2}$ capture. The effects of the primary surface features and the functional groups of the carbon nanofibers on $\mathrm{CO}_{2}$ adsorption capacity were discussed. Results showed that the carbonization temperature influenced the porous texture and the surface chemical states of the carbon nanofibers significantly. The specific surface area, total pore volume, and micropore volume of the fibers increased with increasing carbonization temperature, but the ultra-micropore volume presented a different trend. The samples carbonized at $750{ }^{\circ} \mathrm{C}$ had the smallest average pore hydraulic radius. Moreover, in the micropore range, the volume of sub-micropores increased at a greater rate than that of ultra-micropores after activation. The carbonization temperature was also of great importance in controlling the nitrogen content and composition. $\mathrm{A} \mathrm{CO}_{2}$ uptake of $3.47 \mathrm{mmol} / \mathrm{g}$ at $25^{\circ} \mathrm{C}$ and 1 atm was achieved. The ultramicropore volume of the carbon nanofibers was the most important parameter for determining $\mathrm{CO}_{2}$ uptake at $1 \mathrm{~atm}$; however, the $\mathrm{CO}_{2}$ adsorption capacity at $0.15 \mathrm{~atm}$ was highly dependent on the surface pyrrolic or pyridonic groups.

\section{Introduction}

The combustion of fossil fuels has resulted in the significant release of carbon dioxide $\left(\mathrm{CO}_{2}\right)$ to the atmosphere, which has been regarded as a major contributor to global warming. Since the dependence on fossil fuels still cannot be avoided, $\mathrm{CO}_{2}$ emission control is of vital importance. Many studies have been dedicated to developing carbon capture and sequestration technologies to reduce the emission of $\mathrm{CO}_{2}$ to the atmosphere. ${ }^{(1,2)}$ Currently, absorptionregeneration technologies using amine-based or ammonia-based absorbents are being used in most large-scale commercialized $\mathrm{CO}_{2}$ capture systems. Absorption is an effective method for $\mathrm{CO}_{2}$ capture, but it is accompanied by high energy demand during the regeneration process,

*Corresponding author: e-mail: ycchiang@saturn.yzu.edu.tw

https://doi.org/10.18494/SAM.2020.2871 
corrosion problems, oxidative degradation of the amines, and flow problems caused by viscosity, compelling industry to look for alternative technologies for the removal of $\mathrm{CO}_{2}{ }^{(3)}$

Recently, there has been high interest in studies of $\mathrm{CO}_{2}$ adsorption on porous solid materials. However, the optimization of porous adsorbents for $\mathrm{CO}_{2}$ capture is still in progress. The $\mathrm{CO}_{2}$ adsorption performance is highly influenced by the porous structure and surface functional groups of adsorbents. Hu et al. ${ }^{(4)}$ found that pores smaller than $1 \mathrm{~nm}$ in diameter were the main contributors to high $\mathrm{CO}_{2}$ uptake at atmospheric pressure. These pores with diameters smaller than $1 \mathrm{~nm}$ can be controlled via the activation conditions. Presser et al. ${ }^{(5)}$ reported that pores smaller than $0.5 \mathrm{~nm}$ contributed the most to the $\mathrm{CO}_{2}$ uptake at 0.1 bar, and pores smaller than $0.8 \mathrm{~nm}$ contributed the most at 1 bar. de Souza et al. ${ }^{(6)}$ showed that the $\mathrm{CO}_{2}$ uptake increased linearly with the volume of pores smaller than $0.7 \mathrm{~nm}$. Wickramaratne and Jaroniec ${ }^{(7)}$ observed that a high $\mathrm{CO}_{2}$ capacity of $8.9 \mathrm{mmol} / \mathrm{g}$ at $0{ }^{\circ} \mathrm{C}$ and 1 bar on activated phenolic resin-derived carbon spheres was primarily due to the presence of small micropores $(<0.8 \mathrm{~nm})$.

The incorporation of different nitrogen-containing functional groups onto the surface of porous solid adsorbents is the most commonly used method to improve $\mathrm{CO}_{2}$ uptake. ${ }^{(8,9)}$ Nitrogen enrichment can effectively introduce basic functionalities, hence enhancing the specific adsorbent-adsorbate interactions for $\mathrm{CO}_{2}$ molecules. ${ }^{(10)}$ The nitrogen groups on the adsorbents having a basic character were amine groups and imine groups, so the presence of these groups should lead to higher $\mathrm{CO}_{2}$ capacities, probably partially due to chemisorption. ${ }^{(11)}$ Most studies utilized acid-base interactions to explain the high $\mathrm{CO}_{2}$ uptake on $\mathrm{N}$-doped carbons, while Xing et al. ${ }^{(12)}$ reported another viewpoint in which the hydrogen-bonding interactions between the $\mathrm{CO}_{2}$ molecules and the carbon surface accounted for the high $\mathrm{CO}_{2}$ adsorption on $\mathrm{N}$-doped carbons.

Activated carbon, activated carbon fibers, carbon nanofibers, zeolites, metal organic frameworks, zeolitic imidazolate frameworks, silica adsorbents, and carbon nanotubes have been intensively investigated as potential candidates for $\mathrm{CO}_{2}$ capture. Among these porous materials, carbon nanofibers have shown several advantages over other adsorbents, such as a more concentrated pore size distribution, rapid adsorption rate, short transit distance, excellent adsorption capacity at a low concentration of adsorbates, and a low pressure drop. ${ }^{(13)}$ Compared with conventional activated carbon fibers, activated carbon nanofibers possess more homogeneous and shallower pores. ${ }^{(14)}$

Several process techniques such as electrospinning, self-assembly, phase separation, template synthesis, and drawing have been applied to synthesize polymer nanofibers. ${ }^{(15)}$ Among them, the electrospinning method is a very versatile and efficient technique for fabricating nano- to microscale fibers, which have much smaller diameters than conventional carbon fibers. The average fiber diameter increased with increasing polymer concentration in the precursor solution. ${ }^{(16,17)}$ Xiong et al. ${ }^{(18)}$ prepared polyacrylonitrile (PAN) nanofibers activated at a relatively low activation temperature $\left(500{ }^{\circ} \mathrm{C}\right)$, with a high $\mathrm{N}$ content of $20.9 \mathrm{wt} . \%$ and a $\mathrm{CO}_{2}$ uptake of $2.25 \mathrm{mmol} / \mathrm{g}$ at 1 bar. The pores mainly developed during carbonization and activation, and the surface chemistry was also strongly related to the conditions used for carbonization and activation. ${ }^{(16,19)}$ Although the effect of the carbonization temperature of carbon nanofibers has been discussed in some studies, the activation process after carbonization was not conducted in these studies. ${ }^{(20)}$ Therefore, in this study, we prepared activated PAN 
carbon nanofibers by electrospinning followed by stabilization, carbonization, and activation, and we focused on the effect of the carbonization temperature on the properties and $\mathrm{CO}_{2}$ adsorption performance of the samples. PAN was selected as the carbon precursor because it is one of the most widely used polymers for preparing carbon fibers and has a high nitrogen content and excellent thermal and mechanical properties. The properties of the samples were characterized using several techniques, and the $\mathrm{CO}_{2}$ adsorption on the adsorbents was evaluated. Moreover, the major parameters determining the $\mathrm{CO}_{2}$ uptake were examined statistically.

\section{Materials and Methods}

\subsection{Sample preparation}

Activated carbon nanofibers were synthesized by electrospinning. A $10 \mathrm{wt} \%$ polymer solution was prepared by dissolving PAN $(M W=150000 \mathrm{~g} / \mathrm{mol}$, Sigma-Aldrich $)$ in $N$, $\mathrm{N}$-dimethylacetamide (DMAc, Sigma-Aldrich) while constantly stirring at $60{ }^{\circ} \mathrm{C}$ for $24 \mathrm{~h}$ in order to obtain homogeneous PAN solutions, where the PAN was utilized without further purification. Then the polymer solution was loaded into a syringe with a 23 -gauge spinneret. A syringe pump (NE-1000, New Era Pump Systems, Inc., USA) was used to dispense the polymer solution at a feeding rate of $1.0 \mathrm{ml} / \mathrm{h}$. The anode of the high-voltage power supply (FESHV30, Falco Tech Enterprise Co., Ltd, Taiwan) was clamped to a syringe needle tip, and the cathode was connected to a stainless steel cylindrical collector $(\varnothing 15 \mathrm{~cm})$. The applied voltage was $10 \mathrm{kV}$ and the tip-to-collector distance was kept constant at $10 \mathrm{~cm}$. Then the solution was electrospun using an electrospinning system (FES-COS, Falco Tech Enterprise Co., Ltd, Taiwan). The electrospun nanofibers were collected on a cylindrical collector (300 rpm) covered with aluminum foil. The as-spun PAN fibers were stabilized in air at $280{ }^{\circ} \mathrm{C}$ for $12 \mathrm{~h}$ in a muffle furnace using a heating rate of $1{ }^{\circ} \mathrm{C} / \mathrm{min}$. The carbonization of stabilized nanofibers was conducted in a tubular furnace at four different temperatures $\left(650,750,950\right.$, and $\left.1050{ }^{\circ} \mathrm{C}\right)$ with a heating rate of $5{ }^{\circ} \mathrm{C} / \mathrm{min}$ under flowing nitrogen of $100 \mathrm{sccm}$, and the temperature was maintained for $1 \mathrm{~h}$. Then the carbonized fibers were activated at $850{ }^{\circ} \mathrm{C}$ for $2 \mathrm{~h}$ in a $\mathrm{CO}_{2}$ atmosphere $(100 \mathrm{sccm}) . \quad \mathrm{CO}_{2}$ activation generates a larger pore volume percentage in the micropore range and a higher yield of the product, so $\mathrm{CO}_{2}$ was chosen as the activating agent. The carbonized samples were labeled as NFx, with $x$ indicating the carbonization temperature. The activated samples were denoted as NFxa.

\subsection{Characterization}

The morphology of the samples was observed by field emission scanning electron microscopy (FESEM) in a microscope (S-4700, Hitachi, Krefeld, Germany). The surface features of the samples were probed from $\mathrm{N}_{2}$ adsorption-desorption isotherms measured at $-196{ }^{\circ} \mathrm{C}$ using an accelerated surface area and porosimetry (ASAP) apparatus (ASAP2020, Micromeritics, Norcross, GA, USA). The specific surface areas of the samples were measured at relative pressure $\left(P / P_{o}\right)=0.05-0.3$ by the Brunauer-Emmett-Teller (BET) method. The 
micropore $(<2.0 \mathrm{~nm})$ surface area $\left(S_{m i}\right)$ was determined by the t-plot method. The singlepoint total pore volume $\left(V_{t}\right)$ was obtained at $P / P_{o} \approx 0.99$. The micropore and ultra-micropore $(<0.7 \mathrm{~nm})$ volumes (denoted as $V_{m i}$ and $V_{u l t r a}$, respectively) were calculated by applying the nonlocal density functional theory (NLDFT). X-ray photoelectron spectroscopy (XPS) was applied to determine the number and type of functional groups present on the surface of the samples. The XPS spectra of the samples were obtained using a spectrometer (PHI 5000 VersaProbe II, ULVAC-PHI, Kanagawa, Japan), where a scanning X-ray monochromator (A1 anode, $h v=1401 \mathrm{eV}$ ) was used and the information on elements within a few nanometers of the sample surface could be obtained. A nonlinear least squares curve-fitting program (XPSPEAK software, version 4.1, The Chinese University of Hong Kong, Hong Kong, China) was used for the deconvolution of the XPS $\mathrm{N}_{1 \mathrm{~s}}$ spectra.

\section{3 $\mathrm{CO}_{2}$ adsorption experiments}

The $\mathrm{CO}_{2}$ adsorption experiments were carried out on selected samples at 25,40 , or $55{ }^{\circ} \mathrm{C}$ under a $\mathrm{CO}_{2}$ pressure of less than $120 \mathrm{kPa}$ using a Micromeritics ASAP 2020 system. The $\mathrm{CO}_{2}$ uptake was measured by the volumetric method. $\mathrm{CO}_{2}$ gas with a high purity of $99.999 \%$ was supplied by a gas cylinder. A sample of about $0.05 \mathrm{~g}$ was used in experiments. In our previous work, ${ }^{(21)}$ the Freundlich equation [Eq. (1)] provided a good fit to $\mathrm{CO}_{2}$ adsorption data on carbon nanofibers, so it was used in this study to fit the adsorption isotherms of $\mathrm{CO}_{2}$ on the selected samples accordingly.

$$
q_{e}=K_{F} P^{1 / n}
$$

Here, $K_{F}\left[(\mathrm{mmol} / \mathrm{g})(1 / \mathrm{kPa})^{1 / n}\right]$ is the Freundlich adsorption coefficient and $\mathrm{n}$ is a constant indicating the isotherm curvature. The isosteric heat of adsorption $\left(Q_{s t}\right)$ is a measure of the interaction between adsorbate molecules and adsorbent lattice atoms and can be used as a measure of the energetic heterogeneity of a solid surface. ${ }^{(22)} Q_{s t}$ can be calculated by the Clausius-Clapeyron equation as follows:

$$
-\frac{Q_{s t}}{R}=\frac{d \ln P}{d \frac{1}{T}},
$$

where $Q_{s t}(\mathrm{~kJ} / \mathrm{mol})$ is the isosteric heat of adsorption, $R(=8.314 \mathrm{~J} / \mathrm{mol} / \mathrm{K})$ is the gas constant, and $T(\mathrm{~K})$ is the adsorption temperature.

\section{Results and Discussion}

\subsection{FESEM images}

FESEM images of the samples are shown in Fig. 1. The average fiber diameters of the carbonized samples decreased from about $500 \mathrm{~nm}$ (NF650) to $330 \mathrm{~nm}$ (NF1050) with increasing 


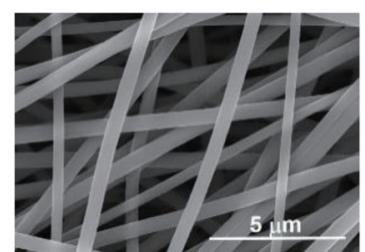

(a)

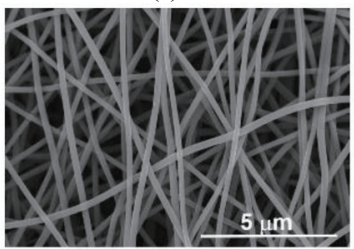

(e)

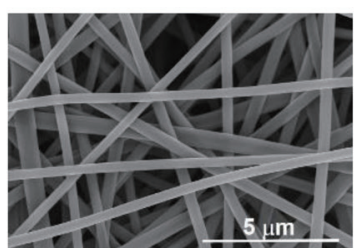

(b)

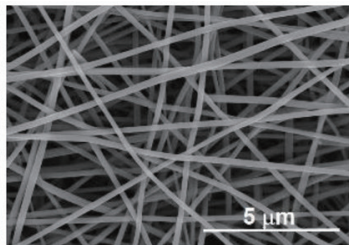

(f)

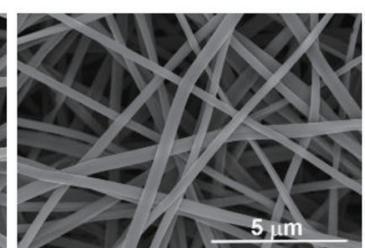

(c)

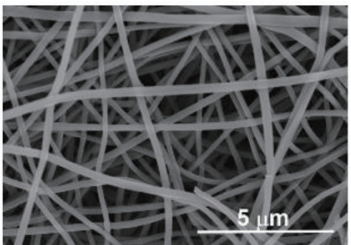

(g)

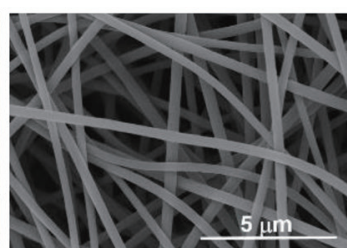

(d)

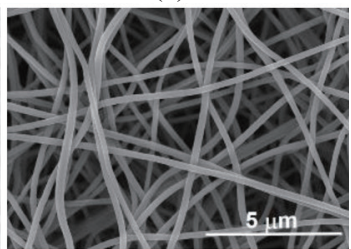

(h)

Fig. 1. FESEM images: (a) NF650; (b) NF750; (c) NF950; (d) NF1050; (e) NF650a; (f) NF750a; (g) NF950a; (h) NF1050a.

carbonization temperature. Carbonization is a process in which the material is heated in the absence of air to a temperature high enough to drive off volatile materials and produce solid porous carbon. When the carbon nanofibers were successively activated, the size of the carbon nanofibers was in the order NF750a $(194 \mathrm{~nm})<$ NF650a $(201 \mathrm{~nm})<$ NF1050a $(214 \mathrm{~nm})<$ NF950a $(220 \mathrm{~nm})$. The smaller average fiber diameters of NF650a and NF750a were attributed to their carbonization temperatures being lower than the activation temperature. It is believed that the samples carbonized at 650 and $750{ }^{\circ} \mathrm{C}$ were relatively unstable during the activation process at $850{ }^{\circ} \mathrm{C}$ because the carbonization temperature was lower than that activation. Therefore, after activation, not only were large internal and external surface areas generated, but also a greater decrease in the fiber diameter was observed.

\subsection{Surface features}

The calculated surface textural properties of the samples determined from $\mathrm{N}_{2}$ adsorptiondesorption isotherms at $-196{ }^{\circ} \mathrm{C}$ are summarized in Table 1, which indicates that the samples were intrinsically microporous, even the unactivated ones. The values of $S_{B E T}, S_{m i}, V_{t}$, and $V_{m i}$ generally increased with increasing carbonization temperature for both carbonized and activated samples. Furthermore, there was a noticeable increase in micropore surface area and volume after activation. However, the largest $V_{\text {ultra }}$ occurred for NF950 among the carbonized samples and for NF650a among the activated samples. The average pore hydraulic radius was the smallest on the samples carbonized at $750{ }^{\circ} \mathrm{C}$. After activation, the development of ultra-micropores slowed down with increasing carbonization temperature, or even the ultramicropores expanded to sub-micropores. Among the carbonized samples, NF750 exhibited the largest ratios of micropore (as well as ultra-micropore) area and volume. After continued activation, NF750a still had the largest ratio of micropore area, but the largest ratio of micropore (as well as ultra-micropore) volume was observed for NF650a. This indicated that activation 
Table 1

Surface porous properties of the samples determined by $\mathrm{N}_{2}$ adsorption-desorption isotherms at $-196{ }^{\circ} \mathrm{C}$.

\begin{tabular}{lcccccccccc}
\hline Sample & $\begin{array}{c}S_{B E T^{(i)}} \\
\left(\mathrm{m}^{2} / \mathrm{g}\right)\end{array}$ & $\begin{array}{c}S_{m i}{ }^{(\mathrm{ii})} \\
\left(\mathrm{m}^{2} / \mathrm{g}\right)\end{array}$ & $\begin{array}{c}V_{t}^{(\mathrm{iii})} \\
\left(\mathrm{cm}^{3} / \mathrm{g}\right)\end{array}$ & $\begin{array}{c}V_{m i}{ }^{(\mathrm{iv})} \\
\left(\mathrm{cm}^{3} / \mathrm{g}\right)\end{array}$ & $\begin{array}{c}V_{\text {ultra }}{ }^{(\mathrm{iv})} \\
\left(\mathrm{cm}^{3} / \mathrm{g}\right)\end{array}$ & $\begin{array}{c}r_{M P}(\mathrm{v}) \\
(\mathrm{nm})\end{array}$ & $S_{m i} / S_{B E T}$ & $V_{m i} / V_{t}$ & $V_{\text {ultra }} / V_{t}$ & $V_{\text {ultra }} / V_{m i}$ \\
\hline NF650 & 188 & 146 & 0.1108 & 0.0786 & 0.0629 & 0.34 & 0.78 & 0.71 & 0.57 & 0.80 \\
NF750 & 306 & 259 & 0.1795 & 0.1567 & 0.1280 & 0.28 & 0.85 & 0.87 & 0.71 & 0.82 \\
NF950 & 473 & 389 & 0.2802 & 0.2404 & 0.1829 & 0.32 & 0.82 & 0.86 & 0.65 & 0.76 \\
NF1050 & 531 & 402 & 0.3213 & 0.2660 & 0.1705 & 0.30 & 0.76 & 0.83 & 0.53 & 0.64 \\
NF650a & 673 & 558 & 0.3582 & 0.3156 & 0.2276 & 0.47 & 0.83 & 0.88 & 0.64 & 0.72 \\
NF750a & 872 & 744 & 0.4318 & 0.3798 & 0.2233 & 0.45 & 0.85 & 0.88 & 0.52 & 0.59 \\
NF950a & 976 & 779 & 0.5116 & 0.4136 & 0.2122 & 0.49 & 0.80 & 0.81 & 0.41 & 0.51 \\
NF1050a & 1175 & 758 & 0.6142 & 0.4784 & 0.1680 & 0.55 & 0.65 & 0.78 & 0.27 & 0.35
\end{tabular}

${ }^{(i)}$ Specific surface area $\left(S_{B E T}\right)$ was determined by the BET method. ${ }^{(i i)}$ Micropore area $\left(S_{m i}\right)$ was obtained using the t-plot method. ${ }^{\text {(iii) }}$ Total pore volume $\left(V_{t}\right)$ represents the single-point total pore volume at $P / P_{o} \approx 0.99$. ${ }^{\text {iv) }}$ Micropore volume $\left(V_{m i}\right)$ and ultra-micropore volume $\left(V_{\text {ultra }}\right)$ were determined by NLDFT, where ultra-micropore was defined as a pore size less than $0.7 \mathrm{~nm} .{ }^{(v)}$ Average pore hydraulic radius $\left(r_{M P}\right)$ was estimated by micropore analysis (MP).

increased the surface area and pore volume; however, this increase mainly occurred in the nonmicropore range when the carbonization temperature was higher than $750{ }^{\circ} \mathrm{C}$. Moreover, in the micropore range $(<2 \mathrm{~nm})$, the increase in sub-micropore $(0.7-2 \mathrm{~nm})$ volume was greater than that in the ultra-micropore $(<0.7 \mathrm{~nm})$ volume after activation.

The pore size distributions (PSDs) in the micropore range of the samples are illustrated in Fig. 2, which were obtained from NLDFT. Several models are currently available in the NLDFT model library. In this study, two of the models were compared: one was carbon slit pores (slit) and the other one was carbon pores with a heterogeneous surface (based on the two-dimensional version) (HS-2D), as shown in Fig. 2(a). The results indicated that the HS-2D NLDFT model could detect the existence of a peak at about $0.4 \mathrm{~nm}$, but the slit-NLDFT model only could probe down to $0.6 \mathrm{~nm} ;{ }^{(23)}$ thus, the HS-2D-NLDFT model was subsequently used. The PSD patterns of carbonized samples [Fig. 2(b)] indicated that most of the micropores for NF650 and NF1050 were concentrated in the sub-micropore range. Figure 2(c) shows the PSD patterns of activated samples, which indicated that after activation, numerous ultra-micropores were produced in NF650a but the development of sub-micropores was dominant in other activated samples.

\subsection{XPS analysis}

The $\mathrm{C}_{1 \mathrm{~s}}, \mathrm{O}_{1 \mathrm{~s}}$, and $\mathrm{N}_{1 \mathrm{~s}}$ photoelectrons were recorded in the XPS survey scan spectra of the nanofiber samples. The surface atomic percentages and atomic ratios are listed in Table 2. The atomic percent of the $\mathrm{N}_{1 \mathrm{~s}}$ peak decreased with increasing carbonization temperature, and activation led to a significant loss in $\mathrm{N}_{1 \mathrm{~s}}$. Figure 3 shows a comparison of the high-resolution XPS $\mathrm{N}_{1 \mathrm{~s}}$ spectra of carbonized and activated samples. A bimodal pattern was observed in all $\mathrm{N}_{1 \mathrm{~s}}$ spectra. As seen from the figure, the functional groups at the peak of about $398.4 \mathrm{eV}$ were unstable and were preferentially unbounded from the surface at a high temperature. The intensity ratios of the two major peaks in the XPS $\mathrm{N}_{1 \mathrm{~s}}$ spectra $\left(I_{398.4} / I_{401.2}\right)$ decreased in the order NF650 (1.71) > NF750 (1.48) > NF950 (0.56) > NF1050 (0.38) for the carbonized samples and NF750a $(0.92)>$ NF650a $(0.86)>$ NF950a $(0.70)>$ NF1050a (0.4) for the activated samples. 


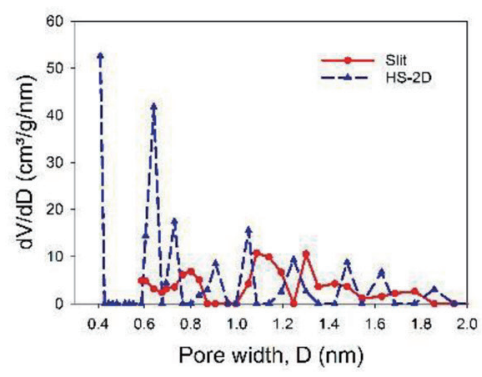

(a)

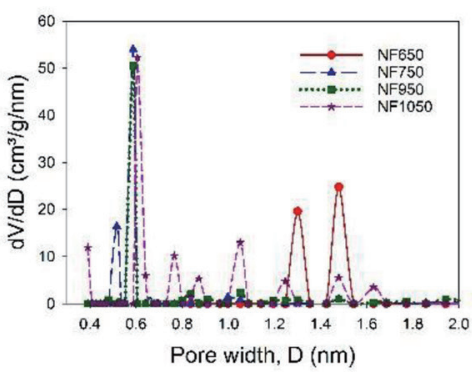

(b)

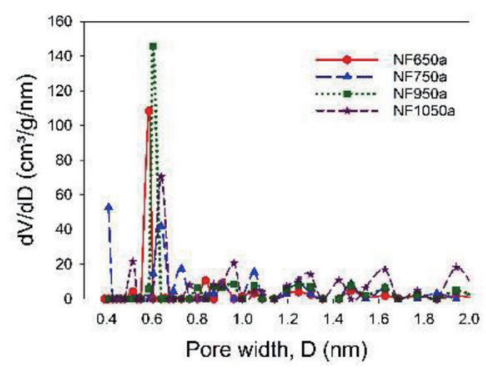

(c)

Fig. 2. (Color online) PSD of the samples. (a) Comparison of the NLDFT models in the micropore range of the samples; (b) carbonized samples; (c) activated samples.

Table 2

Surface atomic percentages and elemental ratios of the samples from XPS analysis.

\begin{tabular}{lccccccc}
\hline \multirow{2}{*}{ Sample } & \multirow{2}{*}{ Yield (\%) } & \multicolumn{3}{c}{ Atomic percent (\%) } & & \multicolumn{2}{c}{ Atomic ratio } \\
\cline { 3 - 4 } \cline { 7 - 8 } & & $C_{1 \mathrm{~s}}$ & $N_{1 \mathrm{~s}}$ & $O_{1 \mathrm{~s}}$ & & $O / C$ & $N / C$ \\
\hline NF650 & 52 & 76.5 & 19.9 & 3.6 & & 0.047 & 0.260 \\
NF750 & 40 & 81.1 & 15.2 & 3.7 & & 0.046 & 0.187 \\
NF950 & 28 & 90.6 & 6.4 & 3.0 & & 0.034 & 0.070 \\
NF1050 & 26 & 94.1 & 3.1 & 2.8 & & 0.029 & 0.033 \\
NF650a & 17 & 88.2 & 7.8 & 4.0 & & 0.046 & 0.088 \\
NF750a & 17 & 87.0 & 6.5 & 6.5 & & 0.074 & 0.075 \\
NF950a & 15 & 89.3 & 4.9 & 5.8 & & 0.065 & 0.054 \\
NF1050a & 11 & 94.7 & 2.8 & 2.5 & & 0.027 & 0.029 \\
\hline
\end{tabular}

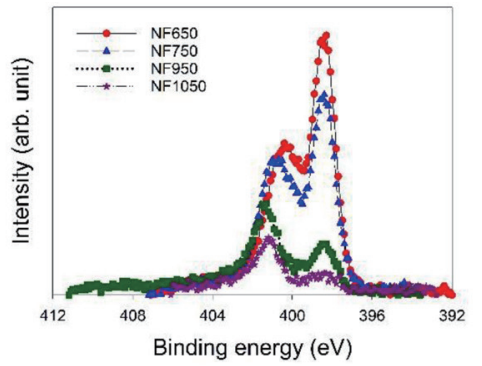

(a)

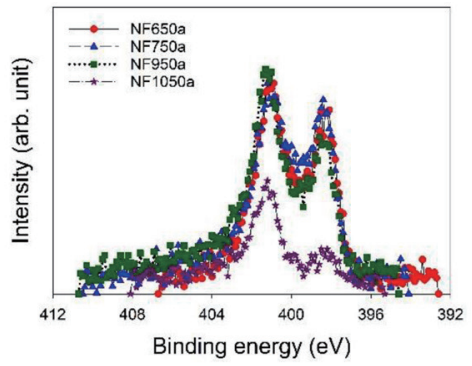

(b)

Fig. 3. (Color online) Comparison of the high-resolution XPS $\mathrm{N}_{1 \mathrm{~s}}$ peaks: (a) carbonized samples; (b) activated samples.

The deconvolution of the high-resolution XPS $\mathrm{N}_{1 \mathrm{~s}}$ spectra for all samples is summarized in Table 3. The $\mathrm{N}_{1 \mathrm{~s}}$ spectra were decomposed into at most seven identified components. As seen from Table 3, the predominant group shifted from the NG2 group (NF650 and NF750) to the NG3 group (NF950) and NG4 group (NF1050) for the carbonized samples as the carbonization temperature increased. Moreover, the atomic percent of the NG3 group had a high value when the carbonization temperature was less than or equal to $950{ }^{\circ} \mathrm{C}$. It is known that pyrrolic $\mathrm{N}$ functions as a polar site, ${ }^{(24)}$ and the nitrogen atom in pyridonic $\mathrm{N}$ is positioned next to the 
Table 3

Results of the fits of the XPS $\mathrm{N}_{1 \mathrm{~s}}$ region for all samples, where values are given in at. \% of total intensity.

\begin{tabular}{lccccccc}
\hline & \multicolumn{7}{c}{ Binding energy (eV) } \\
\cline { 2 - 7 } Sample & 395.7 & 398.4 & 400.1 & 401.2 & 402.4 & 404 & 405 \\
\cline { 2 - 7 } & $\begin{array}{c}\text { Aromatic } \\
\text { N-imines } \\
\text { (NG1) }\end{array}$ & $\begin{array}{c}\text { Pyridine-type } \\
\text { N (NG2) }\end{array}$ & $\begin{array}{c}\text { Pyrrolic or } \\
\text { pyridonic } \\
\text { moieties (NG3) }\end{array}$ & $\begin{array}{c}\text { Quaternary } \\
\text { N (NG4) }\end{array}$ & $\begin{array}{c}\text { Pyridine-N } \\
\text { oxides (NG5) }\end{array}$ & $\begin{array}{c}\text { Shake-up } \\
\text { satellites } \\
\text { (NG6) }\end{array}$ & $\begin{array}{c}\mathrm{NO}_{2} \\
(\text { NG7) }\end{array}$ \\
\hline NF650 & 1 & 49 & 26 & 12 & 9 & - & 3 \\
NF750 & 3 & 43 & 22 & 19 & 10 & - & 3 \\
NF950 & 1 & 14 & 25 & 22 & 9 & - & 30 \\
NF1050 & 4 & 20 & 11 & 30 & 27 & 2 & 5 \\
NF650a & 7 & 29 & 18 & 24 & 16 & 1 & 5 \\
NF750a & 4 & 30 & 18 & 19 & 9 & 1 & 19 \\
NF950a & 3 & 26 & 10 & 23 & 11 & - & 27 \\
NF1050a & 1 & 25 & 4 & 32 & 16 & 2 & 20 \\
\hline
\end{tabular}

$-\mathrm{OH}$ group such that this nitrogen atom is surrounded by more electron groups and behaves as a strong Lewis base. ${ }^{(25)}$ Pyrrolic $\mathrm{N}$ and pyridonic $\mathrm{N}$ are believed to increase the $\mathrm{CO}_{2}$ adsorption capacity. For the activated samples, the NG2 and NG4 groups were the predominant functionalities on all samples. In addition, the $\mathrm{CO}_{2}$ activation introduced many more oxygen atoms onto the fiber surface, leading to the increase in the percentage of oxygen-bound nitrogen functionalities such as chemisorbed $\mathrm{NO}_{2}$ (NG7).

\section{4 $\mathrm{CO}_{2}$ adsorption performance}

On the basis of the fact that the four activated samples had a higher specific surface area than that of carbonized samples and NF750 exhibited the greatest microporosity, especially ultramicroporosity, the above five samples were investigated for their $\mathrm{CO}_{2}$ adsorption performance. The $\mathrm{CO}_{2}$ adsorption isotherms on the selected samples recorded in the pressure range of 0-120 kPa at $25^{\circ} \mathrm{C}$ are compared in Fig. 4(a). At $1 \mathrm{~atm}$, the $\mathrm{CO}_{2}$ uptake decreased in the order NF750a $(3.47 \mathrm{mmol} / \mathrm{g})>\mathrm{NF650a}(3.29 \mathrm{mmol} / \mathrm{g})>\mathrm{NF950a}(3.13 \mathrm{mmol} / \mathrm{g})>\mathrm{NF} 1050 \mathrm{a}(2.77 \mathrm{mmol} / \mathrm{g})$ $>\mathrm{NF} 750(2.52 \mathrm{mmol} / \mathrm{g})$. However, at $0.15 \mathrm{~atm}\left(\mathrm{a} \mathrm{CO}_{2}\right.$ partial pressure typically observed in flue gases), the order was NF750 (1.109 mmol/g) > NF750a $(1.009 \mathrm{mmol} / \mathrm{g})>\mathrm{NF650a}$ $(1.008 \mathrm{mmol} / \mathrm{g})>\mathrm{NF} 950 \mathrm{a}(0.779 \mathrm{mmol} / \mathrm{g})>\mathrm{NF} 1050 \mathrm{a}(0.640 \mathrm{mmol} / \mathrm{g})$. This implied that the surface area and pore volume might be major contributors to the $\mathrm{CO}_{2}$ adsorption at $1 \mathrm{~atm}$, while the $\mathrm{CO}_{2}$ adsorption capacity at $0.15 \mathrm{~atm}$ was controlled by the ultra-microporosity and nitrogen functionalities. The $\mathrm{CO}_{2}$ adsorption isotherms on each sample are shown in Figs. 4(b)-4(f). The amount of adsorbed $\mathrm{CO}_{2}$ decreased with increasing adsorption temperature, indicating that $\mathrm{CO}_{2}$ adsorption on the samples was an exothermic reaction. The curves fitted using the Freundlich equation are also plotted in Fig. 4, which almost overlap with the experimental data. Consequently, the Freundlich equation provided a satisfactory fit for the $\mathrm{CO}_{2}$ uptakes on the carbon nanofiber samples, with $R^{2}$ exceeding 0.997. Compared with previously reported carbon nanofibers prepared under similar conditions (Table 4), the $\mathrm{CO}_{2}$ adsorption capacities on the samples prepared in this study showed satisfactory performance. 


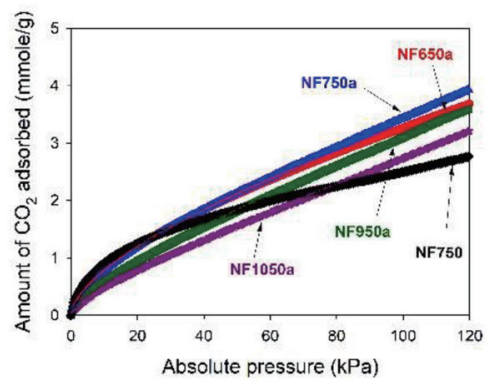

(a)

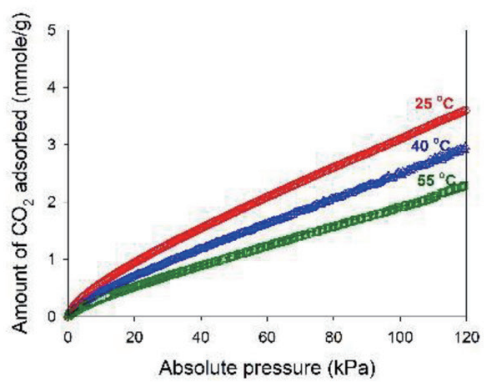

(d)

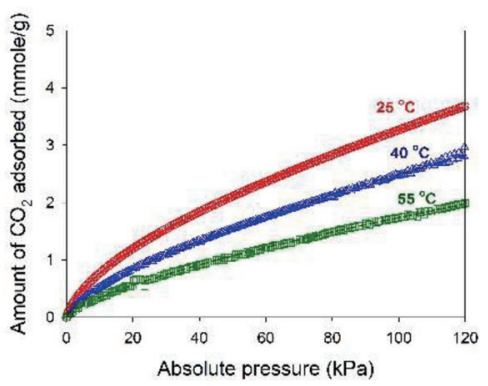

(b)

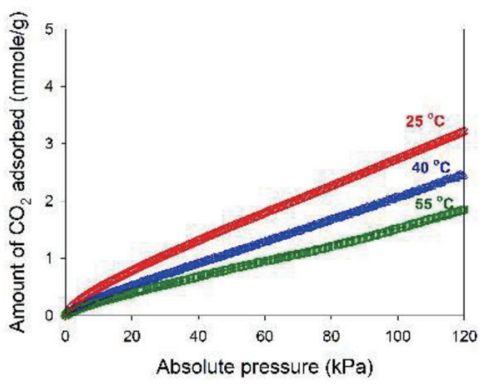

(e)

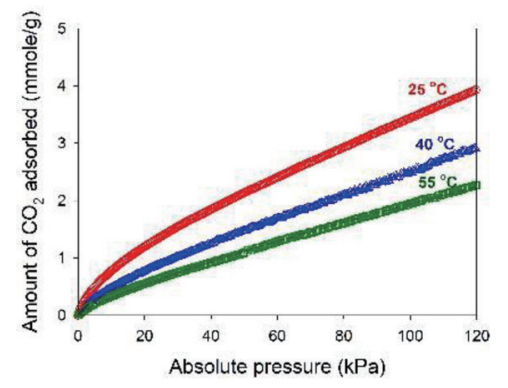

(c)

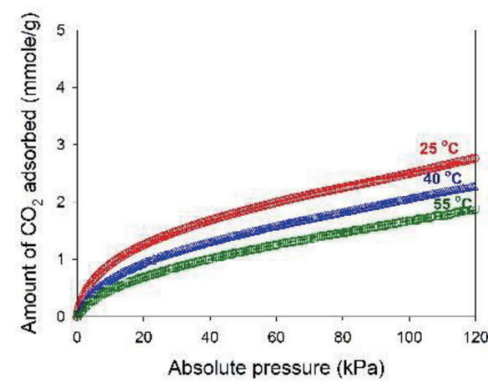

(f)

Fig. 4. (Color online) Adsorption isotherms of $\mathrm{CO}_{2}$ of the samples: (a) all samples at $25^{\circ} \mathrm{C}$; (b) NF650a; (c) NF750a; (d) NF950a; (e) NF1050a; (f) NF750.

Table 4

Comparison of $\mathrm{CO}_{2}$ uptake on the adsorbents in this study with various support materials prepared using electrospinning in the literature.

\begin{tabular}{|c|c|c|c|c|c|c|}
\hline Adsorbent & Precursor & $S_{B E T}\left(\mathrm{~m}^{2} / \mathrm{g}\right)$ & Conc. of $\mathrm{CO}_{2}$ & Temp. $\left({ }^{\circ} \mathrm{C}\right)$ & $\mathrm{CO}_{2}$ uptake $(\mathrm{mmol} / \mathrm{g})$ & Reference \\
\hline $\mathrm{ACNF}^{(\mathrm{i})}$ & PAN & 872 & $\begin{array}{c}1 \mathrm{~atm} \\
0.15 \mathrm{~atm}\end{array}$ & 25 & $\begin{array}{l}3.47 \\
1.01\end{array}$ & This study \\
\hline $\mathrm{CNF}^{(\mathrm{ii})}$ & PAN & 306 & $\begin{array}{c}1 \mathrm{~atm} \\
0.15 \mathrm{~atm}\end{array}$ & 25 & $\begin{array}{l}2.52 \\
1.11\end{array}$ & This study \\
\hline $\mathrm{ACNF}$ & PAN & 486 & $\begin{array}{c}1 \text { bar } \\
0.15 \text { bar }\end{array}$ & 25 & $\begin{array}{l}2.25 \\
1.09\end{array}$ & (18) \\
\hline $\mathrm{CNF}$ & PAN & 12 & 1 bar & 25 & 0.55 & $(26)$ \\
\hline $\mathrm{ACNF}$ & $\begin{array}{c}\text { PAN } \\
\text { polyvinylidene } \\
\text { fluoride }\end{array}$ & 925 & 1 bar & 25 & 2.21 & (26) \\
\hline $\mathrm{ACNF}$ & PAN & 412 & 1 bar & 25 & 0.92 & (27) \\
\hline $\mathrm{ACNF}$ & $\begin{array}{c}\text { PAN } \\
\text { melamine }\end{array}$ & 547 & 1 bar & 25 & 1.44 & (27) \\
\hline $\mathrm{CNF}$ & PAN & 966 & 1 bar & 25 & 2.9 & (20) \\
\hline $\mathrm{ACNF}$ & PAN & 897 & $\begin{array}{c}1 \mathrm{~atm} \\
0.15 \mathrm{~atm}\end{array}$ & 25 & $\begin{array}{l}3.17 \\
1.00\end{array}$ & (21) \\
\hline
\end{tabular}

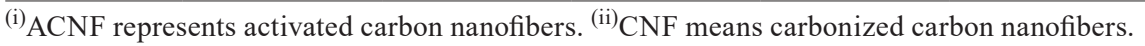

The relationship between the amount of adsorbed $\mathrm{CO}_{2}$ and the $Q_{s t}$ value is shown in Fig. 5. As can be seen from the figure, $Q_{s t}$ decreased log-linearly with increasing $\mathrm{CO}_{2}$ loading from 0.1 to $1.2 \mathrm{mmol} / \mathrm{g}$, which indicated that the interactions between $\mathrm{CO}_{2}$ molecules and the pore walls of the adsorbents were stronger than those between $\mathrm{CO}_{2}$ molecules. ${ }^{(28)}$ Moreover, 


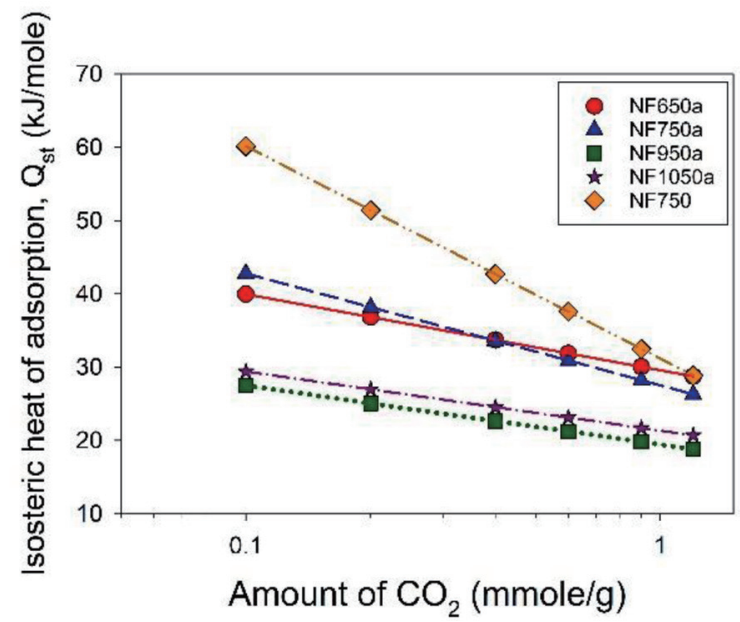

Fig. 5. (Color online) Isosteric heat of adsorption $\left(Q_{s t}\right)$ of $\mathrm{CO}_{2}$ on the samples.

the variation of $Q_{s t}$ with the surface loading also revealed that the active sites on the surface of activated carbon nanofibers for $\mathrm{CO}_{2}$ adsorption were energetically heterogeneous. This means that different levels of surface energy existed. ${ }^{(29)}$ The $Q_{s t}$ values were higher at low $\mathrm{CO}_{2}$ loading, which was attributed to the interactions between $\mathrm{CO}_{2}$ molecules and the basic nitrogen functionalities or the enhanced micropore confinement. ${ }^{(30)}$ The $\mathrm{CO}_{2}$ adsorption on the samples in this study involved physical adsorption.

NF750a, possessing a relatively low specific surface area, displayed the highest $\mathrm{CO}_{2}$ uptake at $25^{\circ} \mathrm{C}$ and $1 \mathrm{~atm}$. On the other hand, NF950a and NF1050a had larger specific surface areas and exhibited lower $\mathrm{CO}_{2}$ adsorption capacities. This indicated that some other factors control the $\mathrm{CO}_{2}$ adsorption in addition to the specific surface area. ${ }^{(8)}$ In order to determine the effect of the adsorption parameters on $\mathrm{CO}_{2}$ adsorption on carbon nanofibers, correlation analysis was carried out. The parameters with a high correlation coefficient with the $\mathrm{CO}_{2}$ uptake were selected to conduct regression analysis, and the regression equation with the highest $R^{2}$ was considered as the optimal model. The results are summarized in Table 5. When the amounts of adsorbed $\mathrm{CO}_{2}$ at 0.15 and 1 atm were both considered, the main factors affecting adsorption capacity were the $\mathrm{CO}_{2}$ pressure and adsorption temperature. At a $\mathrm{CO}_{2}$ pressure of $1 \mathrm{~atm}$, the key parameters were $V_{\text {ultra }}$ and the adsorption temperature, but the dominant factors were pyrrolic or pyridonic groups and the adsorption temperature at a $\mathrm{CO}_{2}$ pressure of $0.15 \mathrm{~atm}$. Excluding the effect of the adsorption temperature, at a $\mathrm{CO}_{2}$ pressure of $0.15 \mathrm{~atm}, V_{\text {ultra }}$ and the pyrrolic or pyridonic groups were the crucial parameters at 25 and $40{ }^{\circ} \mathrm{C}$, but at $55^{\circ} \mathrm{C}$, the $\mathrm{N}_{1 \mathrm{~s}}$ content was the only significant factor. At a $\mathrm{CO}_{2}$ pressure of $1 \mathrm{~atm}$, although $V_{\text {ultra }}$ remained the main factor for $\mathrm{CO}_{2}$ adsorption at 25 and $40{ }^{\circ} \mathrm{C}$, the major parameter shifted to $\mathrm{O}_{1 \mathrm{~s}}$ for $\mathrm{CO}_{2}$ adsorption at $55{ }^{\circ} \mathrm{C}$. As a consequence, the $\mathrm{CO}_{2}$ uptake was highly associated with $V_{\text {ultra }}$ at $1 \mathrm{~atm}$ and the pyrrolic or pyridonic groups at $0.15 \mathrm{~atm}$ at room temperature, in addition to the $\mathrm{CO}_{2}$ pressure and adsorption temperature. 
Table 5

Regression models of the amount of $\mathrm{CO}_{2}$ adsorption amount $(\mathrm{mmol} / \mathrm{g})$ as functions of the parameters.

\begin{tabular}{lclc}
\hline $\mathrm{CO}_{2}$ pressure $(\mathrm{atm})$ & Temperature $\left({ }^{\circ} \mathrm{C}\right)$ & \multicolumn{1}{c}{ Model } & $R_{\text {adjusted }}^{2}(\%)$ \\
\hline $0.15,1$ & $25,40,55$ & $q_{e}=9.32+2.02 P-0.0286 T$ & 92.0 \\
\hline 1 & $25,40,55$ & $q_{e}=14.4-0.0420 T+5.64 V_{\text {ultra }}$ & 93.2 \\
\hline 0.15 & $25,40,55$ & $q_{e}=5.30-0.0153 T+0.103\left[N_{400.1 \mathrm{ev}}\right]$ & 88.9 \\
\hline & 25 & $q_{e}=1.35+8.78 V_{\text {ultra }}$ & 91.3 \\
& 40 & $q_{e}=1.31+5.33 V_{\text {ultra }}$ & 84.1 \\
\hline & 55 & $q_{e}=1.27+0.111\left[\mathrm{O}_{1 \mathrm{~s}}\right]$ & 98.1 \\
\hline \multirow{4}{*}{0.15} & 25 & $q_{e}=0.175+2.59 V_{\text {ultra }}+0.180\left[N_{400.1 \mathrm{ev}}\right]$ & 95.8 \\
& 40 & $q_{e}=0.138+1.62 V_{\text {ultra }}+0.133\left[N_{400.1 \mathrm{ev}}\right]$ & 97.8 \\
& 55 & $q_{e}=0.305+0.0198\left[N_{1 \mathrm{~s}}\right]$ & 89.4 \\
\hline
\end{tabular}

${ }^{*} q_{e}: \mathrm{CO}_{2}$ adsorption amount $(\mathrm{mmol} / \mathrm{g}), P: \mathrm{CO}_{2}$ pressure $(\mathrm{atm}), T$ : temperature $\left({ }^{\circ} \mathrm{C}\right), V_{\text {ultra }}:$ ultra-micropore volume $\left(\mathrm{cm}^{3} / \mathrm{g}\right)$, $\left[N_{400.1 \mathrm{eV}}\right]$ : atomic ratio of the nitrogen functional groups at binding energy $=400.1 \mathrm{eV},\left[O_{1 \mathrm{~s}}\right]$ and $\left[N_{1 \mathrm{~s}}\right]$ : atomic percentages of surface $O_{1 \mathrm{~s}}$ and $N_{1 \mathrm{~s}}$ peaks, respectively.

\section{Conclusions}

PAN-based carbon nanofibers were successfully prepared by electrospinning, with average fiber diameters ranging from 194 to $220 \mathrm{~nm}$ (activated) and from 330 to $500 \mathrm{~nm}$ (only carbonized), large specific surface areas, micropores and ultra-micropores, and high nitrogen contents. It was observed that the carbonization temperature determined the PSD, as well as the predominant type and the distribution of surface nitrogen functionalities. A high carbonization temperature resulted in a lower $\mathrm{N}$ content of the fibers, and the effect of successive activations depended on the carbonization temperature. The highest $\mathrm{CO}_{2}$ adsorption capacity at $25^{\circ} \mathrm{C}$ and $1 \mathrm{~atm}$ was observed on the samples carbonized at $750{ }^{\circ} \mathrm{C}$ followed by physical activation, which was the synergetic outcome of several physical and chemical properties of the adsorbents, which were highly dependent on the preparation conditions. Statistical relationships between the $\mathrm{CO}_{2}$ uptake and the highly associated parameters have been established in this study.

\section{Acknowledgments}

This work was supported by the Ministry of Science and Technology of Taiwan (grant numbers MOST 106-2221-E-155-007-; MOST 108-2731-M-007-001-).

\section{References}

1 S. Y. Lee, and S. J. Park: J. Colloid Interface Sci. 24 (2013) 230.

2 M. Udin Harun Al Rasyid, I.U. Nadhori, A. Sudarsono, and Y.T. Alnovinda: Int. J. Eng. Technol. Innovat. 6 (2016) 79.

3 A. Houshmand, M.S. Shafeeyan, A. Arami-Niya, and W.M.A.W. Daud: J. Taiwan Inst. Chem. E. 44 (2013) 774.

4 X. Hu, M. Radosz, K.A. Cychosz, and M. Thommes: Environ. Sci. Technol. 45 (2011) 7068.

5 V. Presser, J. McDonough, S.H. Yeon, and Y. Gogotsi: Energ. Environ. Sci. 44 (2011) 3059.

6 K. C. de Souza, N. P. Wickramaratne, A. S. Ello, M. J. F. Costa, C. E. F. da Costa, and M. Jaroniec: Carbon 65 (2013) 334.

7 N. P. Wickramaratne and M. Jaroniec: J. Mater. Chem. A 1 (2013) 112. 
8 X. Li, Z. Y. Sui, Y. N. Sun, P. W. Xiao, X. Y. Wang, and B. H. Han: Micropor. Mesopor. Mat. 257 (2018) 85.

9 A. Abbasi, M. M. Nasef, S. Kheawhom, R Faridi-Majidi, M. Takeshi, E. Abouzari-Lotf, and T. Choong: Radiat. Phys. Chem. 156 (2019) 58.

10 C. Pevida, T.C. Drage, and C.E. Snape: Carbon 46 (2008) 1464.

11 M. M. Maroto-Valer, Z. Tang, and Y. Zhang: Fuel Process. Technol. 86 (2005) 1487.

12 W. Xing, C. Liu, Z. Zhou, L. Zhang, J. Zhou, S. Zhuo, Z. Yan, H. Gao, G. Wang, and S. Z. Qiao: Energ. Environ. Sci. 5 (2012) 7323.

13 T. Rojek, L. Gubler, M.M. Nasef, and E. Abouzari-Lotf: Ind. Eng. Chem. Res. 56 (2017) 5925.

14 K. J. Lee, N. Shiratori, G. H. Lee, J. Miyawaki, I. Mochida, S. H. Yoon, and J. Jang: Carbon 48 (2010) 4248.

15 Z. M. Huang, Y. Z. Zhang, M. Kotaki, and S. Ramakrishna: Compos. Sci. Technol. 63 (2003) 2223.

16 H. Tavanai, R. Jalili, and M. Morshed: Surf. Interface Anal. 41 (2009) 814.

17 B. I. Waisi, S. S. Manickam, N. E. Benes, A. Nijmeijer, and J. R. McCutcheon: Ind. Eng. Chem. Res. 58 (2019) 4084.

18 L. Xiong, X. F. Wang, L. Li, L. Jin, Y. G. Zhang, S. L. Song, and R. P. Liu: Energ. Fuel. (in press).

19 Y. C. Chiang, C. Y. Yeh, and C. H. Weng: Appl. Sci.-Basel 9 (2019) 1977.

20 R. Ojeda-López, J. M. Esparza-Schulz, I. J. Pérez-Hermosillo, A. Hernández-Gordillo, and A. DomínguezOrtiz: Fibers 7 (2019) 81.

21 Y. C. Chiang, C. Y. Wu, and Y. J. Chen: Sep. Purif. Technol. 233 (2020) 116040.

22 J. S. Lee, J. H. Kim, J. T. Kim, J. K. Suh, J. M. Lee, and C. H. Lee: J. Chem. Eng. Data 47 (2002) 1237.

23 J. Jagiello, J. Kenvin, A. Celzard, and V. Fierro: Carbon 144 (2019) 206.

24 G. P. Hao, W. C. Li, D. Qian, and A. H. Lu: Adv. Mater. 22 (2010) 853.

25 X. Fan, L. Zhang, G. Zhang, Z. Shu, and J. Shi: Carbon 61 (2013) 423.

26 Y. J. Heo, Y. Zhang, K. Y. Rhee, and S. J. Park: Composites B 156 (2019) 95.

27 D. Jeong, W. Jie, A. A. Adelodun, S. Kim, and Y. Jo: J. Appl. Polym. Sci. 136 (2019) 47747.

28 B. Zhang, J. Yan, and Z. Wang: J. Phys. Chem. C 122 (2018) 12831.

29 P. Ning, F. Li, H. Yi, X. Tang, J. Peng, Y. Li, D. He, and H. Deng: Sep. Purif. Technol. 98 (2012) 321.

30 J. W. F. To, J. He, J. Mei, R. Haghpanah, Z. Chen, and T. Kurosawa: J. Am. Chem. Soc. 38 (2016) 1001. 